\title{
Sobre la distancia como problema
}

ROSALÍA BALTAR Universidad Nacional de Mar del Plata, Argentina

ORCID 0000-0001-5982-5777

rosalia.baltar.letras@gmail.com

ISABEL ALICIA QUINTANA Universidad de Buenos Aires - CONICET, Argentina

ORCID 0000-0003-3816-4089

isaaquintana@gmail.com

\section{Resumen}

En este dossier nos propusimos reunir una serie de trabajos que analizan, revisan, reactualizan la noción de distancia, concepto central para la teoría literaria. Desde el formalismo ruso este concepto retorna en teorías más actuales y en la literatura contemporánea. La distancia supone una toma de posición en el interior de la literatura respecto al objeto abordado en la que se definen lugares de enunciación, se habilitan espacios y subjetividades invisibilizadas. La distancia es un procedimiento que pone a funcionar otras miradas e inscripciones de los cuerpos, y a recuperar vestigios de la memoria que problematizan la temporalidad. La distancia puede ser un repliegue o un campo extendido en continuo movimiento. Contra las nociones fijistas el giro geográfico propuso otra forma de pensar una cartografía que se reconfigura permanentemente fundando otros territorios, y descolonizando otros. La literatura insiste en este ejercicio que es una forma del extrañamiento.

Palabras clave: distancia / memoria / espacio / cuerpos / extrañamiento

\section{About distance as a problem}

Abstract

In this dossier we set out to bring together a series of works that analyze, revise, and update the notion of distance, a central concept for literary theory. From the Russian formalism this concept returns in more current theories and in contemporary literature. The distance supposes a taking of position within the literature with respect to the approached object in which places of enunciation are defined, spaces and invisible subjectivities are enabled. Distance is a procedure that makes other glances and inscriptions on bodies work, and the recovery of vestiges of memory that problematize temporality. The distance can be a retreat or an extended field in continuous movement. Against the fixist notions, the geographical turn proposed another way of thinking, a cartography that is permanently reconfigured by founding other territories and decolonizing others. Literature insists on this exercise that it is a form of estrangement.

\section{Key words: distance / memory / space / bodies /} estrangement 
El rabino de Praga ante su Golem, el Dr. Frankenstein ante su criatura, el carpintero de provincias frente a su Pinocchio: escenas en las que la distancia tiene un protagonismo sustancial. Pero también, Colón desde la orilla, y Solís en El entenado, Ana —la niña de La casa del ángel—frente a sí misma, el antropólogo como autor, las fiestas populares y sus lenguajes frente a la alta cultura, los ojos singulares y la lectura. Para que existan la ironía, la parodia, el chiste y la crítica requerimos de la distancia: entre lo que se dice y lo que se quiere decir, entre un lenguaje diferido y otro inmediato, entre el sentido y su eco. Para que exista la comparación - pongamos por ejemplo el proceso y la transformación de los rituales carnavalescos europeos en el Brasil que estudia Peter Burke (2010) - entre universos, subjetividades y tiempos y espacios, es necesaria la distancia. Por fin, reflexiones sobre mitos, imágenes y representaciones, desde los formalistas a Benjamin, sobre la cultura y el texto anidan en una perspectiva crítica, es decir, en la distancia. Cerca, lejos, vecino, extraño: palabras y conceptos que se desarrollan a partir de cómo son concebidas y representadas las dimensiones espaciales en términos de separación y distancia. Sin embargo, la distancia, como metáfora espacial, habla de la configuración de los objetos de arte y sus contextos de emergencia y la de las distintas apropiaciones y concepciones de la otredad.

Esta pulsión o pasión que nos convoca hoy en este dossier, que podríamos denominar ya no la pasión por lo real sino la pasión por lo espacial tiene su historia cuando el revisionismo geográfico puso en debate nociones tales como las de paisaje, cartografía, representación, frontera, entre otras. Como vemos, algunas tan cercanas a nuestra propia disciplina. A partir de allí la filosofía, la teoría y la crítica cultural comenzaron también a revisar algunas nociones que eran centrales a su pensamiento. No vamos a realizar aquí un recorrido por todas estas reflexiones pero sí subrayar algunas que creemos son todavía productivas para seguir pensando este giro (giro geográfico o espacial). Pensamos, por ejemplo, cómo, retomando el pensamiento de Deleuze y Guattari (2002), Bourriaud (2009) postuló el concepto de «radicante» en tanto forma de repensar ciertas identidades dinámicas definidas a partir de su recorrido. Estas subjetividades se encuentran inscriptas en el entramado de una topografía particular entendida esta como un proceso creativo, en donde el paisaje que se elige habitar es un espacio articulado, emocional y cognitivo. Sin embargo, estas postulaciones que pueden llevar a cierta visión idealizada sobre una nueva forma de habitar y construir espacios encontrarán en la literatura nuevos interrogantes. ¿Hasta dónde es posible sostenerse como sujeto radicante? ¿Cómo puede configurarse un tercer espacio postulado por Soja (1996) en la dimensión poshumana en la que confluyen esas máquinas deleuzianas: la visual (anclada en las redes de la alta tecnología), la del lenguaje (operado desde los medios masivos de comunicación) y la de la guerra (en la que se unen tecnología y massmedia)?

Esta última postulación teórica supone, también, una puesta en suspenso de la noción de distancia como movimiento que genera un tipo de espacialidad. Es decir, ¿asistiríamos en el escenario globalizado a un fin de toda distancia (Ette, 2008)? En la literatura, la cuestión tendrá sus propias resonancias, en tanto se genera una suerte de resistencia a ese fin a través de procedimientos que producen distancias mínimas que se bifurcan constantemente ampliando y deformando el paisaje, los territorios y los mapas. Por otro lado, la cuestión de la distancia encuentra una interesante elaboración teórica en las relaciones que guarda con la noción de intimidad (Pardo, 1996) y en las potencialidades que presenta como elemento que aleja al lenguaje literario del sentido de la comprensión (Blanchot, 1988). De este modo, nos preguntamos ¿cómo 
se articula un espacio que, a la vez, separa una cosa de otra y se encuentra al interior del lenguaje como generalidad impuesta a la experiencia?

Estos planteos surgen de ciertas ficciones que trabajan espacios configurados a partir de la mirada, la indagación en formas de la imagen, la experiencia del viajero o del inmigrante, la confrontación con límites, fronteras o demarcaciones territoriales, la inauguración de topografías en cuerpos habitados por diversas inscripciones o por cuerpos que a través de una performance habitan la ciudad y la redefinen espacialmente. Pero también, la literatura y el arte en general dan cuenta de cómo los propios agentes perciben y se perciben en relación con el espacio en el que trabajan y, a veces, habitan. El espacio no es una instancia abstracta sino el lugar en donde se juegan y disputan diversos imaginarios y subjetividades.

Nos parece necesario retomar la dimensión estética de lo sensible, formulada por Rancière (2000), ya que nos conduce a una reflexión sobre la redistribución de los espacios y su partición en la literatura y otras expresiones estéticas. Para Rancière, la distancia que separa el hecho estético de lo real es lo que permite mantener una dimensión crítica. Esta forma de actuación del arte es una manera de reflexionar sobre el ámbito de lo político como momento de quiebre que posibilita la reasignación de lugares y la reconfiguración de nuevas visibilidades.

Sintetizando, pensar la noción de espacio ligado al problema de la distancia supone, entre otras cuestiones, reflexionar acerca de una serie de interrogantes sugerentes: cuál es el límite, la frontera, la distancia impuesta en los diseños comunitarios; cómo se configuran ciertas geografías como estrategias de representación de sujetos que se desplazan y habitan territorios en su relación conflictiva con ciertas territorialidades; cuáles son los miembros de una comunidad autorizados para hablar y distribuir espacios habitables; cuáles son los sujetos del enunciado, cómo o con qué lengua se los representa; cómo se articulan enunciaciones dispares que llevan a la formulación de imaginarios diferentes y visibilidades diversas; cómo se configuran cuerpos en su relación con el espacio (cuerpos escritos, cuerpos que operan una performance, etc.); qué cuerpos pueden hablar; desde dónde narrar, qué punto de vista se elige, qué distancias o acercamientos se producen entre las voces que confluyen en una narración; cómo se ponen en juego determinados regímenes ópticos desde posiciones de género, de clase social, etc. que determinan los modos de concebir y representar al otro en espacios determinados, qué los agencias, qué los separa, cómo se desarticulan dichas plasmaciones a partir de un trabajo textual y semiótico sobre tales condensaciones simbólicas de nuestra cultura...

En principio, proponemos pensar algunas de estas líneas de análisis a partir de la representación de lo traumático. Dos son los artículos que ubican la distancia en el núcleo de este problema y sus derivas — exilios, desapariciones, memorias — en los movimientos que montajes y traducciones operan en dos textualidades diversas. Por un lado, Estefanía Di Meglio, apoyada en la idea de que la representación se ve justamente intensificada por lo traumático, se centra en esa suerte de danza lingüística que es el relato La resistencia del escritor brasileño Julián Fuks. La naturaleza intervenida de la narración, de las acciones de la lengua y de los espacios y, especialmente, en los vínculos entre la novela familiar procede como un dispositivo representacional que busca potenciar la interferencia, lo interferido como memoria. Las formas de lo tabú y de lo secreto son expresiones, en la novela, de los silencios en las historias individuales o familiares y las macrohistorias, las del devenir social. Es muy interesante observar cómo Di Meglio detecta cierto ritmo, a modo del adagio final «y las olas rompían en la playa» de Virginia Woolf, del que 
se sirve el texto para dar escansión y continuidad, ida y regreso, persistencia y resistencia a las imaginaciones construidas en las gradaciones de la distancia que proyectan los silencios y sus muchos querer callar. En ese camino, María Soledad Boero transita los resquicios de sentido que pueden reconstruirse o desatarse en la película de Albertina Carri, Cuatreros, de 2017. La distancia y los problemas a los que da curso en la cultura audiovisual hacen de la representación un laboratorio de experiencias de archivo, de preguntas acerca de la memoria y de la constitución de cierta novela familiar traumática. Boero se pregunta, ante la proliferación de las imágenes, en consonancia con los mismas interrogantes que exhibe la ficción documental de Carri, por las dimensiones de la vida en términos de archivo de una comunidad, cuyos componentes son tanto materiales cuanto afectivos, emocionales, violentos, de significaciones soterradas. Ambos artículos miden en dos soportes diferentes las distancias entre propósitos y posibilidades reales, los fracasos, tropiezos, en fin, reescrituras y puesta en escena de esos intentos.

Por otra parte, el análisis de María Lourdes Gasillón se centra en otro costado de la distancia; estamos ante un procedimiento que puede dar cuenta de la construcción de lo marginal en la literatura de mitad del siglo XX, la distancia, en términos concretos de procesos de singularización de la vida cotidiana y la mirada extrañada sobre ellos. Dentro de las opciones clásicas de la representación realista, lo marginal y lumpen adquiere en la narrativa de Kordon una perspectiva diferenciada desde dentro, esto es, no como lejanía antropológica para la observación de lo otro en tanto lo exótico, lo disruptivo, sino que la textualidad asume un punto de vista interno y un proceso paródico respecto del discurso impuesto desde fuera. Se trata de una estética, nos dice Gasillón, que trabaja la sensibilidad en relación con el movimiento de las calles, y que asume la toma de la palabra de los marginados como su propia voz.

Dos reflexiones sobre la distancia que ponen a funcionar el espacio en la teoría y en la ficción crítica. Silvana López apela a la noción de lo espacial en la obra de Libertella. En su lectura dicho concepto se convierte en un dispositivo que es inherente a la escritura del autor argentino en diferentes dimensiones. Se trata de las diversas colocaciones de una subjetividad narrativa que fluctúa permanentemente en una cartografía espacial que obliga a reposicionarse y a resignificar relaciones con los otros y con el territorio. Pero también el espacio se convierte en un procedimiento que se va redefiniendo en relación con la escritura. En este caso podría decirse que el espacio es constitutivo de una poética que se piensa y revisa incesantemente. La literatura en este caso se desliza de lo temporal a lo espacial como principio constructivo en donde se arman y desarman series en relaciones tensas y complejas. El trabajo de Rodrigo Montenegro tiene un enfoque teórico. A partir de la noción de distancia que nos remite necesariamente a los formalistas rusos, al teatro de Brecht y a la filosofía de Walter Benjamin, Rodrigo hace un seguimiento riguroso de dicha noción en la que también como procedimiento se actualiza desde diferentes posiciones teóricas y críticas. Se trata de un análisis que busca observar ciertas continuidades, tensiones y apropiaciones desde el ámbito de la teoría pero también de las prácticas vanguardistas y literarias. Pone así en el centro del debate sobre lo espacial una noción que ha sido definitiva en el campo de nuestras prácticas analíticas y artísticas del siglo XX. La distancia emerge como una práctica rupturista que nos obliga a releer los objetos siempre bajo la amenaza de la asimilación comunicativa y la doxa. No solo es fundamental desde el punto de vista de la teoría sino principalmente de las prácticas artísticas. Montenegro muestra cómo el extrañamiento es una práctica y una teoría fundamental en el siglo $\mathrm{XX}$ que atraviesa el siglo y sigue produciendo nuevas reverberaciones. 
Finalmente, queremos agradecer a los autores por sus aportes, no solo para la revista y el campo disciplinar sino, fundamentalmente, para nosotras mismas. Armar, pensar el dossier y luego leer los escritos se constituyó en un escenario de diálogo en el presente contexto problemático y disperso. Y, desde ya, al Taco por darnos esta posibilidad.

\section{Referencias}

Augé, M. (2008). Los «no lugares» espacios del anonimato: una antropología de la sobremodernidad. Barcelona: Gedisa.

Bachelard, G. (1975). La poética del espacio. México: Fondo de Cultura Económica.

Blanchot, M. (1988). The Unavowable Community. Nueva York: Station Hill Press.

Bourriaud, N. (2009). Radicante. Buenos Aires: Adriana Hidalgo.

Burke, P. (2010). La cultura popular en la Europa moderna. Madrid: Alianza.

Deleuze, G. y F. Guattari (2002). Mil mesetas. Capitalismo y esquizofrenia. Valencia: Pre-textos.

Ette, 0. (2008). Literatura en movimiento. Madrid: CSIC.

Pardo, J. (1996). La intimidad. Valencia: Pre-textos.

Rancière, J. (2000). Le partage du sensible. Esthétique et politique. París: La Fabrique.

Soja, E. (1996). Thirdspace: Expanding the scope of the geographical imagination. Londres/Nueva York: Routledge. 